conversation, in which I stated my fears, from the hæmorrhage which had previously taken place, and from the almost total absence of the pulse at the wrist of the injured arm, that the axillary artery and vein had been torn through by the head of the humerus, and that when I should proceed to reduce the dislocation, profuse hæmorrhage would recur, and I should require an assistant possessing anatomical knowledge; therefore I expressed a wish, that a second surgeon should be called in. Amputation, too, I observed, might then be necessary, at the shoulder-joint; but I never contemplated amputatiou, until profuse hæmorthage, following the reduction of the dislocation, proved it to be necessary.

For the sake of showing the healing power of nature, I would observe, that the only applications to the wound during the first week, (the wound being carefully elosed,) were dossils of lint, dipped in cold water. Union by the first intention took place in the greater part of the wound; the synovia, with a small quantity of pus, was discharged at the portion of the wound which was not healed by the adhesive process. I would also observe, in addition to my pupil's account of the cure, that the patient was bled to sixteen ounces on each of the three days following that on which the accident happened; and that the pulse at the wrist of the injured arm returned, when I replaced the head of the humerus in the glenoid cavity of the scapula.

I am, Sir, with great respect for your exertions in behalf of our profession, your obedient servant,

Samuel Millard, M.R.C.S.L.

Whitehurch Asylum, near Ross,

Herefordshire, April 13, 1837.

\section{DISLOCATION OF THE CARPUS, BACKWARDS.}

\section{To the Editor of THE Lancer.}

SIR :-The following case of rare dislocation, which came under my notice on Sa. turday last, may, perhaps, be of sufficient interest for publication in your valuable Journal. I an your obedient servant,

J. Herbert bakker.

House-surgeon, North London Hosp. April 28, 1837.

Hannah Hussey, aged fifteen, admitted April 22. She stated that her right hand was resting upon the end of the heavy box of a mangle, whilst her brother was at the wheel, when it gradually approached a wall behind her, and "jammed" the forearm, lengthways, between the machine and the wall, (the elbow being rgainst the latter, and the hand on the former), producing the dislocation. She immediately came to the hospital, arriving there about a quartes of an hour after the accident, when the nature of the injury was very evident. She suffered great pain. The forearm and hand were in the prone position, and presented a very distorted appearance; the forearm was shortened; there was a remarkable prominence on the back of the radius and ulna; the anterior surface of the first row of carpal bones was lying upon the posterior surface of the ends of the radius and una; above that prominence there was a deep depression, and the prominence itself had an arched appearance, the convexity being towards the elbow; the ends of the radius and ulna were very apparent, on the palmar surface, and the styloid processes were easily distinguished; below these there was another deep depression. The fingers were not rigid; they were supported in the hands of her mother, when she came to the hos. pital. She had not the least power of moving her fingers, or of supining her arm. Mr. Burton and $I$ immediately proceeded to the reduction; he grasped the forearm with both hands, directly below the elbow; I grasped her hand with my right hand, and the wrist with my left, placing the thumb over the dislocated carpal bones. By means of firm extension with my right hand, and pressure with my left,-Mr.Burton coun. ter-extending the arm,- the bones were readily returned to their natural situation, gradually, and without any noise. After the reduction the wrist was exceedingly moveable ; there was, then, not the least effusion, and it was easily ascertained, by a careful examination, that no crepitus existed, and that the moveability did not depend upon fracture of the radius.

The arm was placed in a sling; she was directed to foment the wrist frequently with hot water; and some aperient pills, and a draught, were given to her.

April 23. This morning I went to her residence (No. 9, Little Edward-street, Cumberland-street, Haymarket), and ascertained precisely the manner in which the injury was produced. The mangling-machine is placed alongside one wall of a room, and the frame-work is within three or four feet of a wall, at right angles with the other one, in order to allow of the movements of the heavy box backwards and forwards beyond the frame-work. The box contains a ton and a quarter weight of iron, and is moved upon rollers. Her brother was gently turning the handle, and the girl's right hand was placed upon the end of the box, when her attention was directed to a dog, which she was fearful would frighten some chickens which were in the room; the box gradually approaching the wall, the elbow reached it, and the carpus was dis. located backwards. The brother reversed the direction of the box, immediately that she hallooed "stop," and she came to the 
hospital. No laceration, or bruise, is observed on the elbow.

This morning Mr. Liston examined the arm. There is now great effusion around the joint, extending to about two inches above it, on the palmar surface, not quite so high on the dorsum; there is considerable redness of the integuments ; she cannot extend the fingers in the least, but can flex them a little. She was directed to continue the fomentations; the bowels have been freely opened.

25. There is considerable effusion; the redness is not so great. The arm is kept supported, and fomented frequently.

27. The swelling and redness have much diminished, and she can very slightly extend the fingers, attended with pain along the back of the forearm, to abont its middle; flexion of the fingers is attended with pain along the fore part of the arm. Mr. Liston again made a very careful examination of the wrist, and came to the conclusion that the radius has not been broken.

\section{CASE OF HYDROPHOBIA,}

TREATED INEFFECTUALLY BY

\section{LATE EXCISION, BLEEDING, AND MUSK ENEMA.}

\section{To the Editor of The Lancet.}

SIR:-I send you the following case, interesting, inasmuch as the treatment recommended for its cure was inefficient in the first step, and impracticable in the second. I remain, Sir, your very humble servant, Geo. Tucker.

2, Cardigan Place, Kennington Cross, April 26, 1837.

Mrs. Smith, a married woman, 23 years of age, living at Kennington Cross, was bitten by her own dog, on the 16th of February 1837. She directly applied to a surgeon, who did not excise the parts, in consequence of the abrasions and bites occupying so much surface, but applied caustic to the wounds, which extended round the leg, just above the ancle, and kept the sores open, by irritating ointment, for three or four weeks. She was much alarmed at the time, and then, and afterwards, apprehended that she should die from hydrophobia. She has never been subject to hysteria. On Sunday, April 23d, at 11 1. N., I was called to see her, and found her suffering from an aching pain, all orer her body, but particularly in her legs and the small of her back, with repeated rigors; no headach, or thirst; tongue natural; accelerated, but soft pulse. She had got wet on the previous Thursday, to which cause she attributed her illness.

Supposing it to be a coming attack of influenza, I desired her to put her feet in warm water, and go to bed. Immediately on my leaving her, she retched violently, without bringing any thing from her stomach, and from that moment she felt a diffi. culty in swallowing; however, sle took two pills, composed of equal parts of colocynth and calomel, but upon some liquid medicine being presented to her, she pushed it away with feelings of the greatest aversion, ex. pressing her fears that she should be choked.

This state continuing, I was called up at 5 A. M. on the 24 th, by her husband, who stated that he was fearful that she was rabid. On presenting a cup to her, a most severe paroxysm supervened, and left no doubt of the nature of the malady. The countonance was now anxious and haggard, and assumed a leaden hue, very similar to the blue stage in cholera, and she was fearfully alive to the nature of her situation. I suggested to her, on the recommendation of Mr. Youatt, in the $2 d$ volume of THE LANCET, 1831-5, p. 715, that the parts should be cut out, as affording her the only chance of recovery. To this she consented, and at 10 o'clock, A. M., I cut away, freely, all the parts where any scars remained of the sores made by the dog's teeth; she expressed but little suffering on the occasion; incleed, she was much too quiet. The parts had pricked for a day or two preceding this, but were not altered in colour, nor were they swollen. I then bled her to faintness, taking away about twenty ounces of blood. The paroxysms abated much from this time, for an hour, when, on attempting to rub in some liniment composed of two drachms of pow. dered opium, and two ounces of compound camphor liniment, on the chest, throat, and spine, they returned with such violence, and her sufferings were so acute, that she would not allow any thing more to be attempted at present. After washing off the liniment, she again became more calm, the paroxysins were less frequent, and less strong, and she put a lemon-drop into her mouth, the juice of which gave her great relief. This was the first thing that she had swallowed since taking the pills on the previous evening. I endeavoured to persuade her to swallow some vinegar, from time to time, as recommended by M. Dubetat, who cured a case after the constitutional symptoms had manifested themselves, as reported in THE $\mathbf{L}_{\mathrm{AN}}$. Cer, vol. 2., 1833-4, page 234. She was, however, unable to take any thing but the lozenge, or a bit of sugar, moistened in vinegar, and so she continued, until she died, at 2 r. M. She remained tranquil, if undisturbed, and had slight acressions on any thing being offered to her for sustenance. The muscles were more relaxed, and the countenance lost the leaden hue.

At the suggestion of Mr. Townley, a neighbouring practitioner, I persuaded her to let me throw up an enema, composed of 